の宾氣をここから漏洩した結果收率は著しく下がつた。表

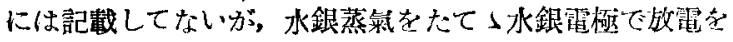
行つた場合に娄收率は向上しなかつた。

\section{3. 富驗結果に關する考察}

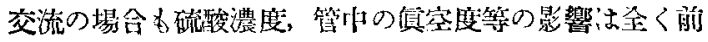
捗の直流の場合と等しく，穴の收率仗直流 $5 \mathrm{~g} / \mathrm{kWh} る に$

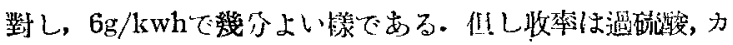

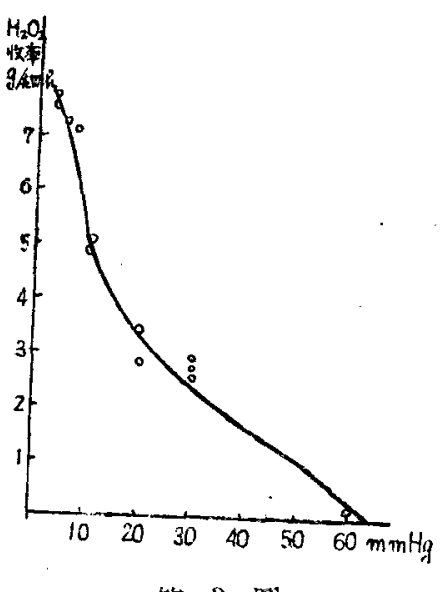

第 3 眭

- - 酸的穴 1 分

子办漨酸化水素

1 分子支加熱心上 り生ずるので, 過 硫䠛，力口一酸を。 過酸化水溸に換算 L住星宗 L た. 分析は硫酸第 一鐵アンモニア法 による。

放電管小の氠空

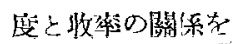

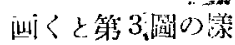

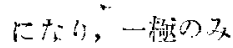

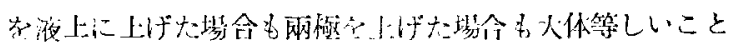
ガ制る。

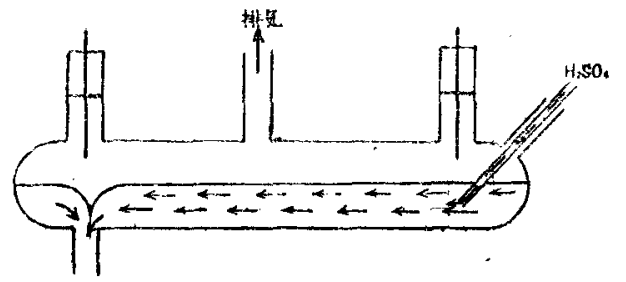

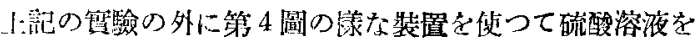
流しなから放電電解を行つた。この特には流速が早いと流 わ落ちる管の内部力浾く，䇒かなO-H帶のスへクトルを見

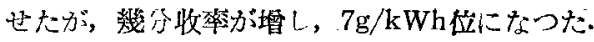

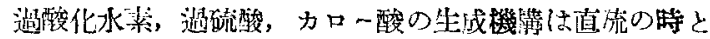
全く闲じせする。

\section{4. 結喜}

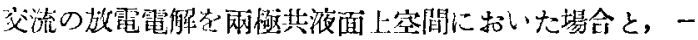

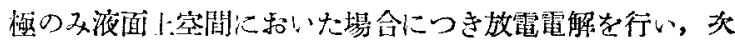
の事筫者知つた。

(1) 磁酸濃度，真空度等の影響は全く淔流の特と同じ

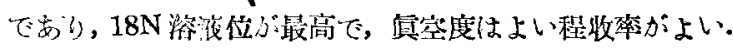

(2) 收涂は直流より艾流の方力㙨分上く，硫踆夜を流 与と倫多少壖与。

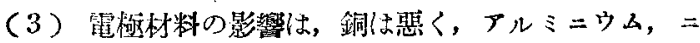

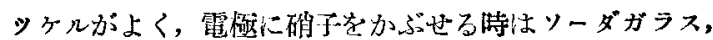
领ガラスかよいか，不英がラス，モリブデンガラス等は收

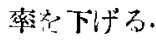

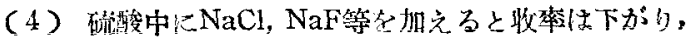

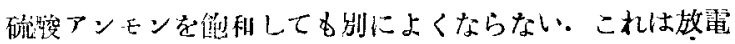

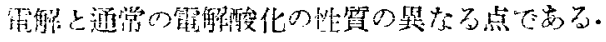

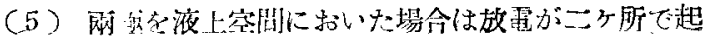

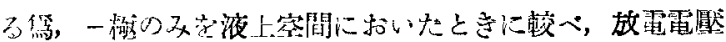

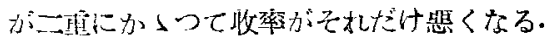

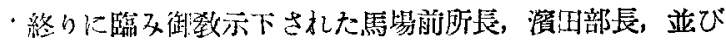

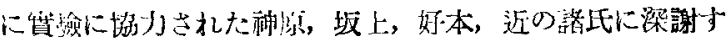
る.

(昭科23年7月14日栄理)

\section{文 噳}

(1) A. Klemenc. : Z. phys. Chem., A 183, 297(1938)

\title{
電壓滴定とその應用（第7報） 勞作尿前後の電壓滴定に及ぼす影響
}

\author{
阿知波繁 一
}

(莨根工筆專門學校)

Potentiometric Titrátion and its Application (Part 7)

The Influence of Labor Urine upon Potention metric Titration.

\section{Shigeichi Achiwa}

(Hikone Technical College, Shiga Pref.)

As a preparatory experiment for the next series, investigations are made on the influence of gelatin upon the precipitation method; $-\mathrm{Cu}^{++}+\mathrm{CN}^{-} \mathrm{Ag}^{+}+\mathrm{Cl}^{-}$ $\mathrm{Pb}^{++}+\mathrm{Fe}(\mathrm{CN})_{0}=\mathrm{Hg}^{++}+\mathrm{I}^{-}$,

(Received 21, Dec. 1948)

\section{1. 緒官}

ゼラチンは泌激反倠に對し 保護膠質としての作用があ

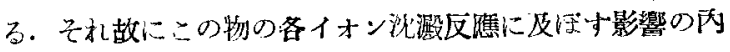

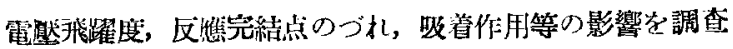




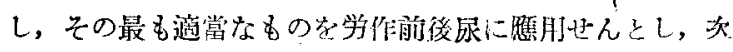
の筫驗を行つた。

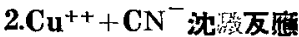

菑駩 $1 \frac{\mathrm{N}}{10} \times 0.8939 \mathrm{CuSO}_{4} 1 \mathrm{Ccc}$ と $1 \%$ ぜシチン溶葆を $0,2,5,10,20,40,60,80,100 \mathrm{cc}$ 割合に混合し，これを $\frac{\mathrm{N}}{10} \times 0.97796 \mathrm{KCN}$ て滴定した。銀指示電娆迹用，滴定滥度

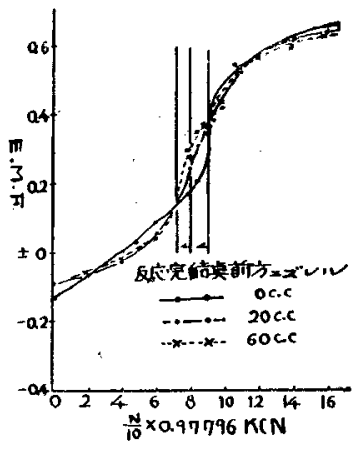

第 1 圖 $20^{\circ} \mathrm{C}$.

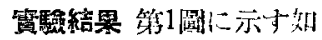
くゼラチンの情加するる程霜 傿飛躍点, 则ち反應終結点 の移䣦苍來たした・今ビラ チン含有量と反隼筧結理諭 值加らの穏動 $\mathrm{KCNec}$ 數と の關系宗圆示すると第 2圖 曲線厂の如く，單位ゼラチン の $\mathrm{Cu}^{+}$吸着聂の變化及び電

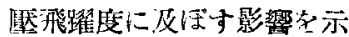
寸と同汕線II, III“の如くな

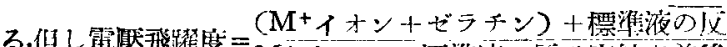

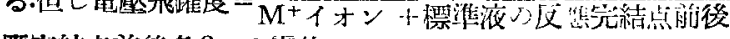

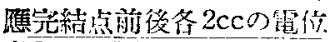
各2 $2 \mathrm{cc}$ 電位

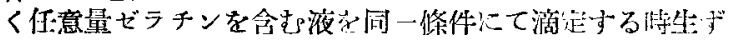

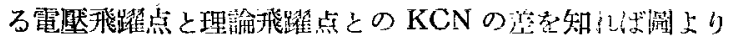

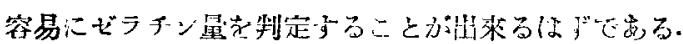

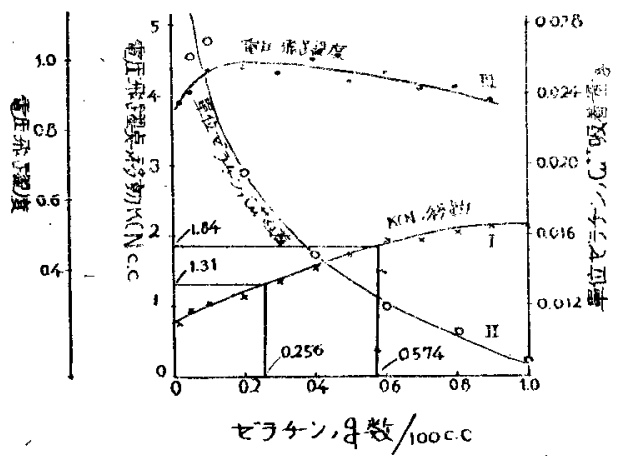

籍 2 阔

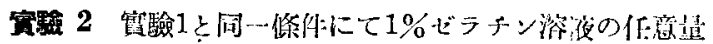

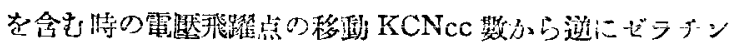
量をみた。

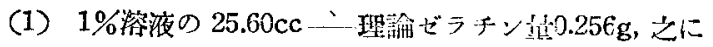
對少るKCNの移動 $\mathrm{cc}$ 數 $1.31 \mathrm{cc}$

(2) " $57.40 \mathrm{cc}-0.574 \mathrm{~g}$, $1.84 \mathrm{cc}$

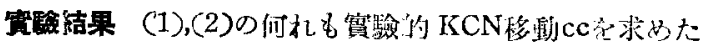
のに何れる1.3,1.84ccとなり，是く一效せる結森を示した。

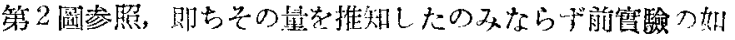

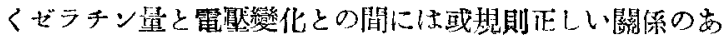
ること袁震㳻している。

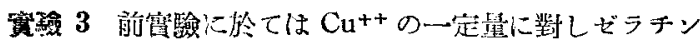

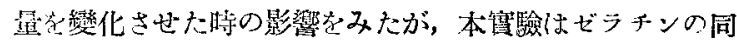

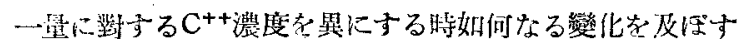
かをみた若しこの結果反隹完結点のつれれ，穴の他何れる

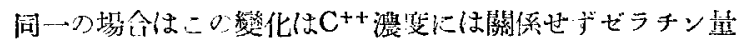

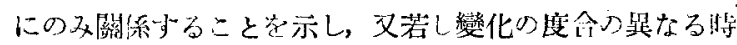
はCu+十滑度心關系与ることと示すことになる。

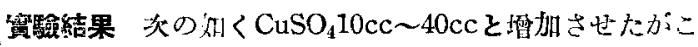

\begin{tabular}{|c|c|c|c|}
\hline $\begin{array}{c}{ }^{N} \times 0.89385 \\
\mathrm{CuSO}_{4} \\
\text { 採取量 } \mathrm{cc}\end{array}$ & $\begin{array}{c}\mathrm{N} \times 0.97796 \\
\mathrm{KCN} \\
\mathrm{KCN} \\
\text { 理墖 } \mathrm{Cc}\end{array}$ & 阔 & 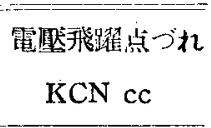 \\
\hline 10 & 9.14 & 7.80 & 1.34 \\
\hline 20 & 18.28 & 17.00 & 1.28 \\
\hline 40 & 36.56 & 35.22 & 1.34 \\
\hline
\end{tabular}

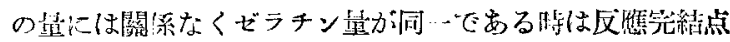

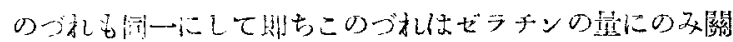
保守ること知つた。

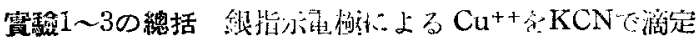

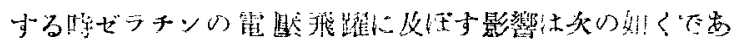
2 .

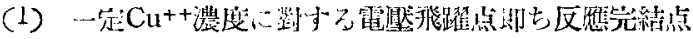

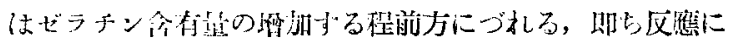

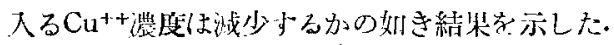

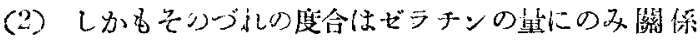
L $\mathrm{Cu}^{++}$漲度心は關䋆しない。

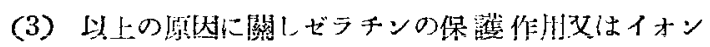
吸着作州によるものと思われる。

(4) 任意含有ゼラチン量の推定も可指ですう.

(5) 電国飛躍度は徐々に娍少する.

\section{3. $\mathbf{A g}^{+}+\mathrm{Cl}^{-}$沈洪反鹰}

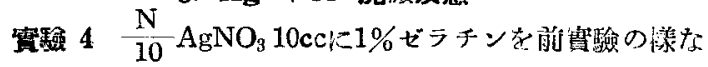

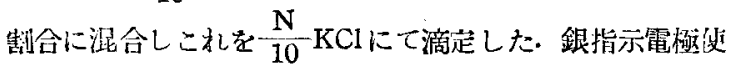
用, 滴定溫度 $20^{\circ} \mathrm{C}$

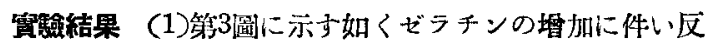

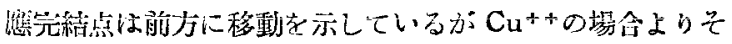

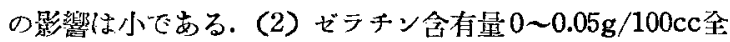

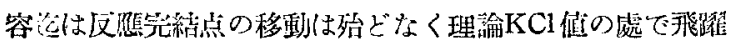

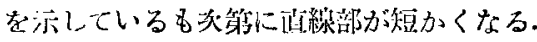

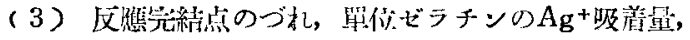

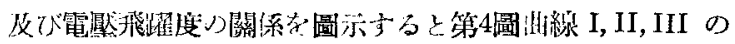
如くなる。

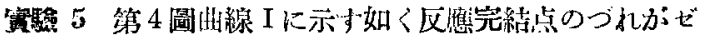




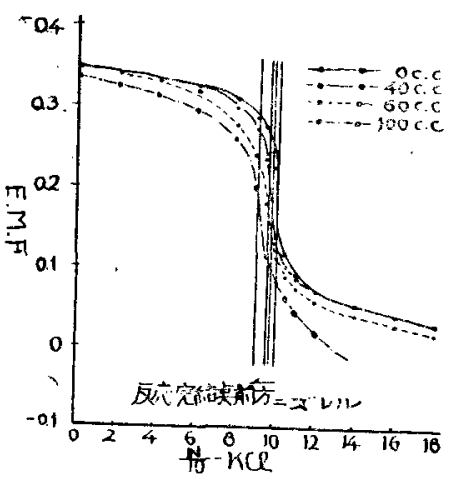

第 3 圖

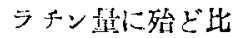
例して變化与る蛙

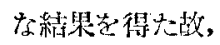

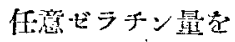
含む液を滴定して 作圖より逆に求め t.

(1) $1 \%$ テチ ン溶液 $51.80 \mathrm{cc}$ 理緰ゼラチン量 $0.518 \mathrm{~g}$,光に對する $\mathrm{KCl}$ の移度 $\mathrm{cc} 0.45 \mathrm{cc}$

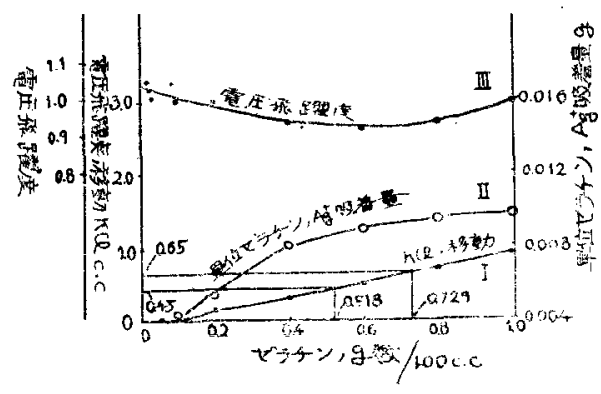

笌 $\frac{1}{2}$ 国阴

(2) $1 \%$ アチン溶淮 $72.90 \mathrm{cc}$ 一理渝ゼラチン点

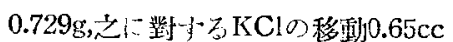

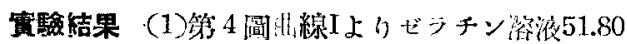

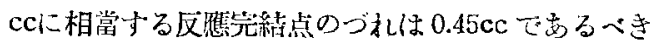

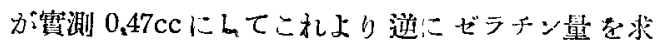
めたのに $0.520 \mathrm{~g}$ 部害+0.39\%

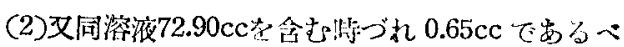

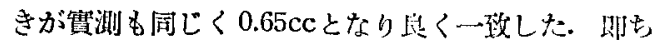
反僬完結点のづれより通にだラチン量を推知なるこ とが出來ると思われる。

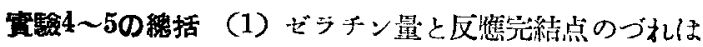

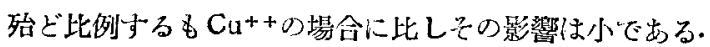

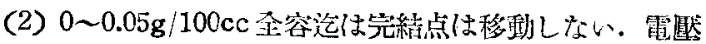

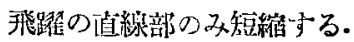

(3) 任意ゼラサン量も推起し得る。

(4) W. D. Treadwell, S. Tanett, W. Blumenthol 等:

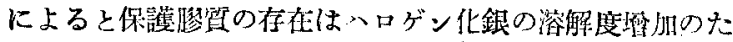

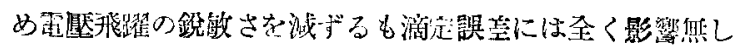

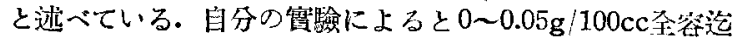

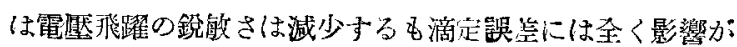

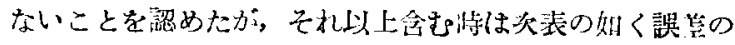

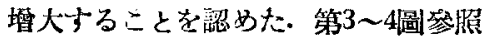

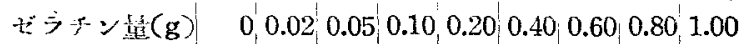

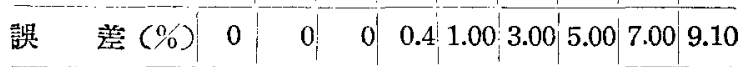

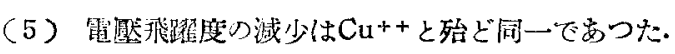

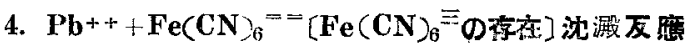
蜜驗 $6 \frac{\mathrm{N}}{10^{-}}-\mathrm{Pb}\left(\mathrm{NO}_{3}\right)_{2}$ の10ccとゼラチンの各混合比を

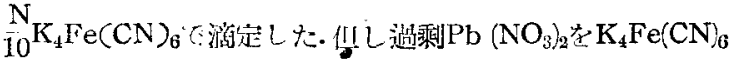

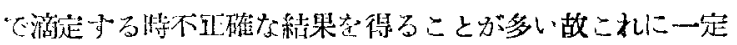

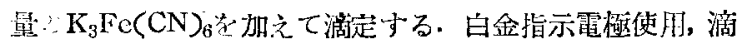
定溫度 $20^{\circ} \mathrm{C}$.

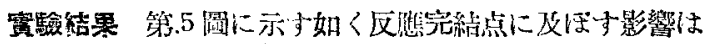

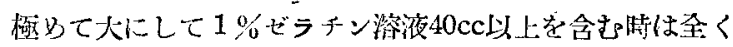

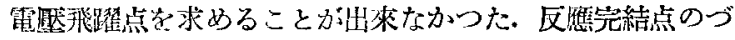

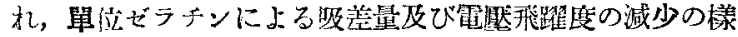
子を示子と第6圆の奶くなりその何孔も極めて大なる影響

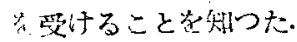

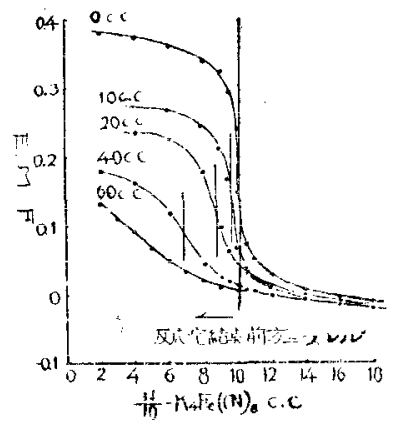

第 5 圆

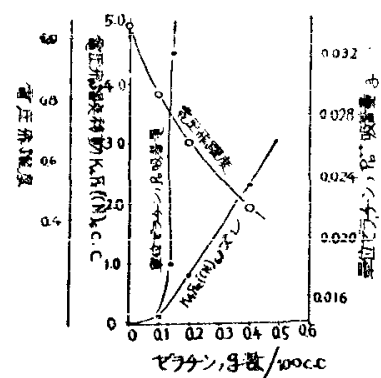

第 6 圖

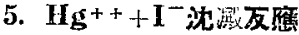

零驗 $7 \frac{\mathrm{N}}{10} \mathrm{HgCl}_{2}$ の $10 \mathrm{cc}$ とゼラチンの等混合液を $\mathrm{N}$

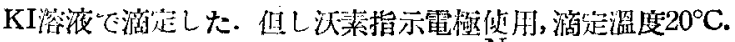

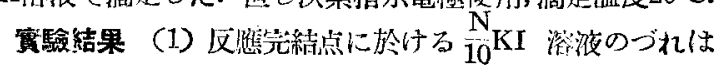
$\mathrm{Cu}, \mathrm{Ag}, \mathrm{Pb}$ それに比し催少でする。

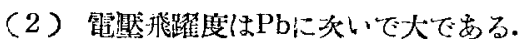

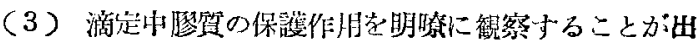
来る.

6. 尿(酸性, アルカリ性, 中性)十金靨イオン反隹

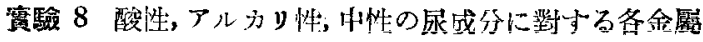
イインの反隹をみた。

\begin{tabular}{|c|c|c|c|}
\hline イオン 液性 & 打些 & 酸性 & アルカリ性 \\
\hline $\mathrm{Ag}^{+}$ & 沈 & 沈 & 浓 \\
\hline $\mathrm{Hg}^{++}$ & ナシ & ナシ & 沙 \\
\hline $\mathrm{Cu}^{++}$ & 浓 & ナシ & 湤 \\
\hline $\mathrm{Pb}^{++}$ & 沈 & ナシ & 液 \\
\hline
\end{tabular}




\section{7. 結 論}

ゼラ:ンの $\mathrm{Cu}^{++}+\mathrm{CN}^{-}, \mathrm{Ag}^{+}+\mathrm{Cl}^{-}, \mathrm{Pb}^{++}+\mathrm{Fe}$

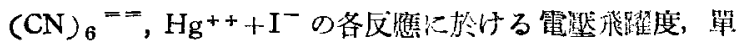

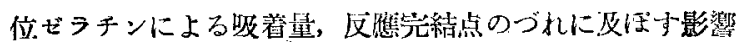
を總括して圖示すると第 9〜11圖の如くで

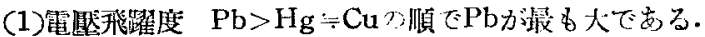

(2)反㷪完結点のづれ $\mathrm{Pb}>\mathrm{Cu}>\mathrm{Ag}>\mathrm{H}_{\mathrm{g}}$ の順で $\mathrm{Pb}$ 急速に河加它示している。これに對しHgはぜラチンの或 量以上はからつてづれのKIccc數の減少を示す.

(3)單位ゼラチンの各イホン吸着量 $\mathrm{Pb}$ は敀速に埼加し Agは極めて徐々に榴加子る.Cuは急速に娍少しその後は徐 々に減少， $\mathrm{Hg}$ 最初上り徐令減少する。

（4)反隹完絈点決定の難易 この難易は湖線中重淔部の多 程容易であるからこれより見るに次の膜序である.Ag， $\mathrm{Hg}, \mathrm{Pb}, \mathrm{Cu}$ 但し前 3 者はその美少なく何孔も終点省容吸 に決定出來るがCuは困鹳である。

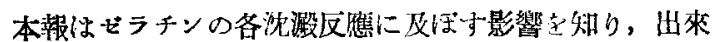

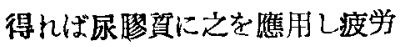
湘定上何等かの意義を見出そ弓 とするのであるから尿膠筫が裝 も艮くその金㯺イオンす吸着し その量の變化が最も鋭敞に電盟 飛躍度に又又隹筞等点のづれの 上に現われ，且つ筞結点に於け

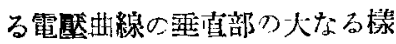

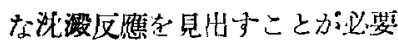
條牛である.然るに他方尿成分 と金屬イオンとの反䧺当考慮こ 入れなければならない。即り尿 成分と沈澱在起さない金呞イオ

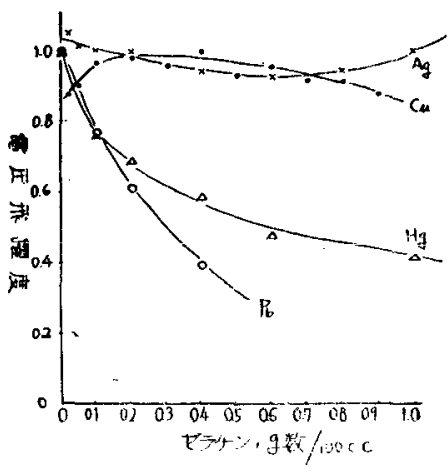

第 9 圖

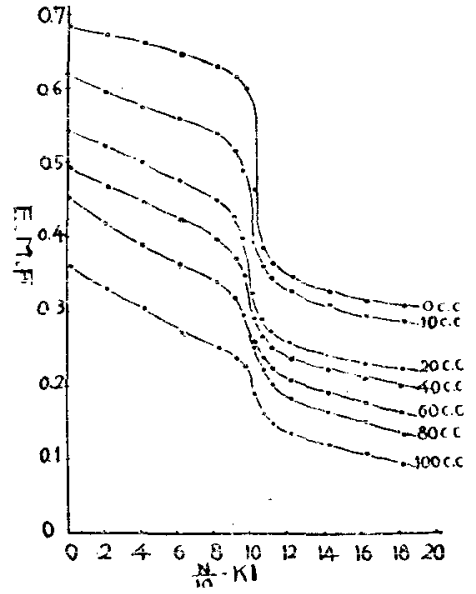

第. 7 圖
ンといえば自づから或限定を受けることになる。故に本韩

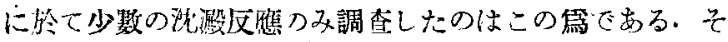

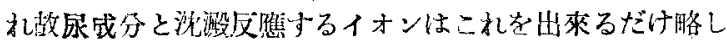
たのである。

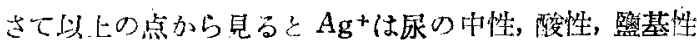

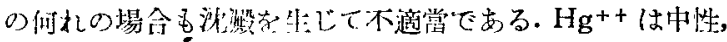

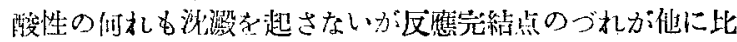

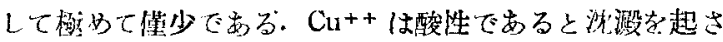

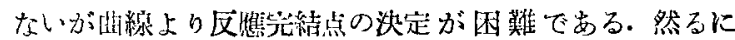

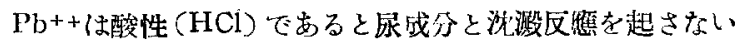

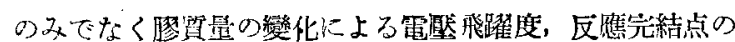

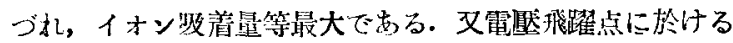

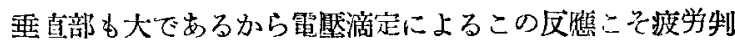
定の一助となり得るといわ施る尿珍筫の多少を推知す るに最も適した反焦と思われる。炏報はこの應用による調 查主報告する.(昭和23年12月21日受理)

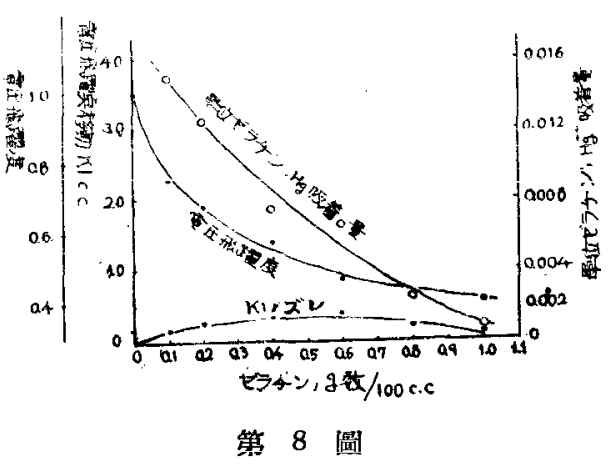

第 8 温

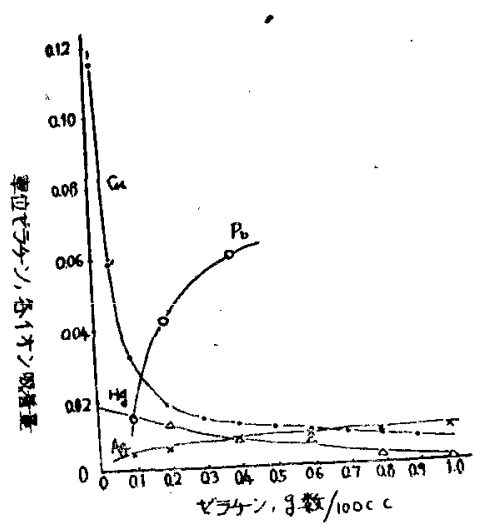

第 11 第

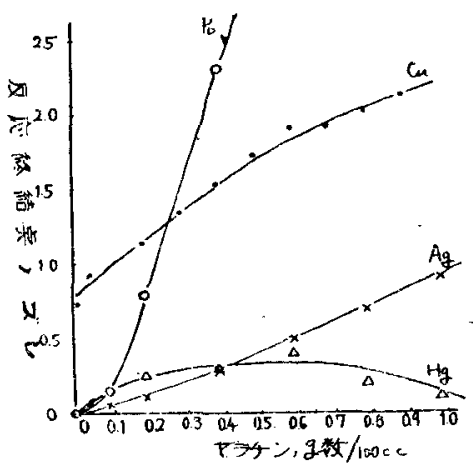

籍 10 圆 